Original Research Paper

\title{
Novel Production of Two New Nonpolyenic Antifungal Macrolide Derivatives by Streptomyces Z26 Isolated from Moroccan Rhizospheric Soil
}

\author{
${ }^{1,2}$ Ahmed Nafis, ${ }^{1}$ Brahim Oubaha, ${ }^{1}$ Najoua Elhidar, ${ }^{2}$ Nico Ortlieb, \\ ${ }^{2}$ Andreas Kulik, ${ }^{2,3}$ Timo Niedermeyer, ${ }^{1}$ Lahcen Hassani and ${ }^{1}$ Mustapha Barakate \\ ${ }^{1}$ Laboratory of Biology and Biotechnology of Microorganisms, \\ Faculty of Sciences Semlalia, Cadi Ayyad University, PO Box 2390, Marrakech, Morocco \\ ${ }^{2}$ Interfaculty Institute of Microbiology and Infection Medicine (IMIT), \\ Eberhard Karls Universität Tübingen, Germany \\ ${ }^{3}$ Institute of Pharmacy, Pharmaceutical Biology, \\ Martin-Luther-University Halle-Wittenberg 06120 (Saale), Germany
}

Article history

Received: 25-01-2018

Revised: 01-03-2018

Accepted: 08-3-2018

Corresponding Author:

Lahcen Hassani

Laboratory of Biology and

Biotechnology of

Microorganisms, Faculty of

Sciences Semlalia, Cadi Ayyad

University, PO Box 2390,

Marrakech, Morocco

E-mail: 1hassani.ced@gmail.com

\begin{abstract}
The aim of our study was to screen Moroccan actinomycete isolates able to produce nonpolyenic antifungal metabolites in order to contribute to limiting the problem of fungal infections emergence in particular mycotic diseases and to discover known antifungal families, especially nonpolyenic drugs. 480 isolates were tested against 5clinically pathogenic Candida species. Several methods have been used to study the polyenic or non-polyenic nature of the antifungal molecules produced by Actinobacteria (i) The study of the antibacterial activity (the bacterial plasma membrane is devoid of sterols); (ii) The screening of the antimicrobial activity of resistant strains to polyenic antifungals essentially Candida tropicalis $R 2$ and Pythium irregular; (iii) The inhibition of antifungal activity by exogenous ergosterol addition in the culture medium and (iv) The UV-Visible light spectrophotometric analysis of the crude extracts of the actinomycete isolates. Among all isolate tested, only 60 (29 $\%$ ) showed an antifungal activity against all test microorganisms used. Six active isolates meet all the selection criteria and produced nonpolyenic antifungal metabolites. The taxonomic study of the promising isolate Z26, using morphological, physiological and molecular characters, showed that it has $99,43 \%$ of similarity with Streptomyces phytohabitans but there were some differences in morphological characteristics. In addition, the chemical study, using chromatographic and spectroscopic techniques, of the bioactive substances produced in the Z26 isolate fermentation broth in NL300 culture medium allowed the determination of two macrolide derivatives with chemical structures $\mathrm{C}_{62} \mathrm{H}_{100} \mathrm{O}_{24}\left(\mathrm{~m} / z\right.$ 1251.6504 $\left.[\mathrm{M}+\mathrm{Na}]^{+}\right)$ and $\mathrm{C}_{68} \mathrm{H}_{110} \mathrm{O}_{26}\left(\mathrm{~m} / z\right.$ 1365.7174 $\left.[\mathrm{M}+\mathrm{Na}]^{+}\right)$. NMR experiments revealed that the active compounds were Novonestmycin A and B. The Novonestmycins $\mathrm{A}$ and $\mathrm{B}$ are for the first time produced by an actinomycete strain purely isolated from the Moroccan ecosystems.
\end{abstract}

Keywords: New Nonpolyenic Antifungal, Clinically Pathogenic Yeasts, Moroccan Actinomycetes, Novonestmycins

\section{Introduction}

From the early 1980s, human diseases are mainly caused by the emergence of fungi, especially at the immuno-compromised and those with serious diseases. These fungal infections are essentially caused by Candida species. Some study revealed that these infections have a very considerable mortality and morbidity and it is obvious that fungal diseases have appeared as the most dangerous public health problems in the world (Diekema and Pfaller, 2004; Vandeputte et al., 2012).

A trend analysis of mortality due to infectious diseases reports a high increase in mortality due to 
several reasons mainly to mycoses and the majority of these mycoses related deaths were attached with Candida species infection (McNeil et al., 2001).

Numerous factors contribute to the increased fungal infections. The most important is an immunecompromised ever-expanding population because of the rupture of the mucosal or cutaneous barrier, defects in cell-mediated immunity or in the function and of number neutrophils and extremes of age (Dutta et al., 2015).

Antifungal compounds are playing an important role to control the mycotic diseases but they are a very small in number but significant group among the different types of dominant drugs in the market (Atta, 2010). However, many substances, polyene ones in particular, cannot be useful in therapy because of their toxicity, while they are very interesting in agriculture, industry and animal therapy, such as amphotericin B (Laniado-Laborín and Cabrales-Vargas, 2009).

The major challenge for the pharmaceutical industry today is to find new, safe, less toxic and more effective non-polyenic antifungal compounds in order to counter the aggressive increase of opportunistic infections. Moreover, the interest in discovering new molecules has increased with the development of new ideas and approaches, such as the use the new sources of bioactive materials, like marine sponges, microorganism of soil and plants from several ecological niches (Behie et al., 2016).

Actinomycetes provide many interesting bioactive substances of high commercial value and continue to be regularly screened for new bioactive molecules (Barakate et al., 2002). Also, according to the pioneering work of Selman Abraham Waksman; they are known for their ability to produce medically useful antibiotics (Gebreyohannes et al., 2013).

Among all the genera of actinomycetes, the genus Streptomyces is most found in nature with a high number of strains that can synthesize drugs and bioactive substances (Manivasagan et al., 2013). In fact, 70\% of the known antibiotics are produced by this genus (Procópio et al., 2012) and many representatives of this group produce molecules of high commercial value in fields like as anticancer, antitumor, anti-inflammation therapy and are being widely screened for novel bioactive compounds (Manivasagan et al., 2014).

Actinomycetes are used in the fermentation of active pharmaceutical compounds, such as the antifungal ones, anti-cancer, antiviral, agents of immuno-suppressor, weed killers, etc. (Hashimoto, 2007). But, exploring new ecosystems is one of the most interesting ways to isolate new strains of actinomycetes having new antimicrobial activities (Wadetwar et al., 2013).

The objective of the present study was to search the antifungal nonpolyenic compounds produced by actinomycete isolates from different rare Moroccan ecosystems, to do the taxonomic identification of the selected isolate and to purify and elucidate the structure of the active molecules which it produces.

\section{Materials and Methods}

\section{Selection of Actinomycete Isolates Producing Antifungal Substances}

480 actinomycete isolates, originatingfrom various Moroccan ecosystems, such as rhizospherical soil, endophytic plants, Atlas Mountains soil and Sahara sand, were used in this study. Five clinically yeast species, obtained from the Moroccan Coordinated Collections of Micro-organisms in the National Center for Scientific and Technical Research Morocco (CNRST), were used as test strains (Table 1). The selection of actinomycete strains with antifungal activity was realized by agar diffusion method in Sabouraud medium at $28^{\circ} \mathrm{C}$ (Ismet et al., 2012).

Isolates were grown on Bennett's agar plates $(10 \mathrm{~g} / \mathrm{L}$ glucose (Merck), then a calibrated agar cylinder $(6 \mathrm{~mm}$ in diameter) was cut out and placed on Sabouraud agar, which had previously been seeded with each yeast test organism. The plates were kept at $4^{\circ} \mathrm{C}$ for $4 \mathrm{~h}$, the inhibition zones were measured at $28^{\circ} \mathrm{C}$ after $24-48 \mathrm{~h}$ of incubation (Barakate et al., 2002).

\section{Screening for Actinomycete Isolates Producing Nonpolyenic Antifungal Compounds}

The selection of isolates producing only nonpolyenic antifungal metabolites was carried out using four tests:

- Antibacterial activity of actinobacteria isolates was estimated by the agar cylinders method in MuellerHinton media (Merck) (Lee and Hwang, 2002), against two Gram negative bacteria (Pseudomonas aeruginosa DSM 50090, E. coli ATCC 8739) and three Gram positive bacteria (Staphylococcus aureus 209 PCIP 53156, Micrococcus luteus ATCC381 and Bacillus cereus ATCC 14579).These strains were obtained from our laboratory collection. Plates were kept at $4{ }^{\circ} \mathrm{C}$ for $2-4 \mathrm{~h}$ and then incubated at $37^{\circ} \mathrm{C}$ for 18-24 h. The Inhibition zoneswere then measured (Lemriss et al., 2003)

- Activity against Candida tropicalis R2 DSM11953 and Pythium Irregular (CIP18), obtained from the collection of laboratory of Biology and Biotechnology of Microorganisms, Cadi Ayyad University, both are resistant to amphotericin B and nystatin (polyenic antifungals)

- Ergosterol inhibition was tested by both agar diffusion method with or without ergosterol at $50 \mathrm{mg} / \mathrm{mL}$ in the presence of C. albicans L4 (Ouhdouch et al., 2001). The results were compared with those obtained with amphotericin B at $20 \mu \mathrm{g} /$ well

- UV- spectra of active extracts dissolved in methanol were recorded at 220-440 nm with a UV spectrophotometer (Double Beam UV6300 PC, VWR) and compared with those of known polyenic antifungal 
Table 1: Origin of the clinically yeast strains used us microorganisms test

\begin{tabular}{ll}
\hline Yeast strain & Origin \\
\hline Candida albicans L4 & Vaginal sampling \\
Candida glabrata L7 & \\
Candida krusei L10 & Human blood \\
Candida parapsilosis L18 & Human skin \\
Candida albicans L61 & Human esophagus \\
\hline
\end{tabular}

\section{Morphological, Physiological and Molecular Identification of the Actinomycete Isolate}

The morphological proprieties of the isolates were established at $30^{\circ} \mathrm{C}$ after 3 weeks of incubation on ISP media (International Streptomyces Project), ISP1, ISP2, ISP3 and ISP4 media and the production of melanoid pigments was tested at ISP6 and ISP7 agar after 7 days of incubation at $28^{\circ} \mathrm{C}$ (Ayari et al., 2012).

The capacity of isolates to use various carbohydrates sources was determined on ISP basal medium 9 supplemented with $1 \%(\mathrm{w} / \mathrm{v})$ of different carbon sources. Petri dishes were incubated at $28^{\circ} \mathrm{C}$, the growth was determined after two weeks. The isolate's capacity to use several nitrogen sources was tested using a minimal medium; adding by filtration the sterile nitrogen source $(1 \% \mathrm{w} / \mathrm{v})$ (Benouagueni and Kirane, 2016).

The growth in the presence of different concentrations gradient of $\mathrm{NaCl}(1.5-30 \%)$ was determined on ISP2 agar. The ability, of actinomycete isolate, to grow at $\mathrm{pH} 5$ to 10 and at a temperature range of 25 to $50^{\circ} \mathrm{C}$ was tested (Benouagueni and Kirane, 2016). All these biochemical and physiological tests were performed and analyzedafter 2 weeks. Petri dishes were evaluated visually for little or no observable growth $(-)$, moderate $(++)$, or excellent growth $(+++)$.

The genomic DNA used for the PCR analysis was prepared from the single colonies grown on Bennett medium for 3 days. The extraction of genomic DNA was conducted using PeqGold Bacterial DNA Kit (Germany) according to the manufacturer instructions. The isolated DNA was checked for purity and quantified according to standard procedures (Kumar et al., 2010).

Two sets of primers, 27F bac (AGAGTTTGATCMTGGCTCAG) and 1492 Runi (TACGGYTACCTTGTTACGACTT), were used in this study for amplification of $16 \mathrm{~S}$ rRNA gene fragment of the active antibiotic-producing isolates. The final $50 \mu \mathrm{L}$ volume of reaction mixture contained $1 \times \mathrm{PCR}$ buffer $(10$ mMTris- $\mathrm{HCl}, 50 \mathrm{mMKCl}, \mathrm{pH} 9.0$ at $25^{\circ} \mathrm{C}$ ), DMSO $2 \mu 1$, $1 \mu \mathrm{l}$ each dNTP, $1 \mu \mathrm{l}$ each primer, $1 \mu \mathrm{l}$ Q5 polymerase and $1 \mu \mathrm{L}$ of purified DNA.

PCR amplification was carried out using the thermocycler programmed as follows: A hot start of $95^{\circ} \mathrm{C}$ for $5 \mathrm{~min}$, followed by 30 cycles of amplification at $95^{\circ} \mathrm{C}$ for $1 \mathrm{~min}$, annealing at $54-55^{\circ} \mathrm{C}$ for $1 \mathrm{~min}$, extension at $72^{\circ} \mathrm{C}$ for $2 \mathrm{~min}$ and extra extension at $72^{\circ} \mathrm{C}$ for $10 \mathrm{~min}$. Finally, the tubes were held at $4^{\circ} \mathrm{C}$ for direct use, or stored at $-20^{\circ} \mathrm{C}$ until needed.

The PCR product was detected by $1 \%(\mathrm{w} / \mathrm{v})$ agarose gel electrophoresis and was visualized by Ultraviolet (UV) fluorescence after staining at ethidium bromide (Kathiravan et al., 2016). Electrophoresis was performed out at 110 Volts for 45 minutes. The size of the PCR products was estimated using $1 \mathrm{~Kb}$ DNA ladder (Promega, USA).

After sequencing, the RNA $16 \mathrm{~S}$ sequences of the isolates were compared to those of the NCBI nucleotide database using the BLAST algorithm. The Clustal W is used to align the sequences with the highest similar nucleotide percentage and a phylogenetic tree was constructed using the neighbor-joining method with the Mega 6 software (Suardana, 2014).

\section{Chemical Characterization of Active Compounds}

\section{Fermentation and Extraction of Active Molecules}

A single colony of the strain Z26 was used as an inoculum of $500 \mathrm{ml}$ Erlenmeyer flask containing $100 \mathrm{~mL}$ of NL300 medium (Mannitol 20g (Merck), cotton seed $20 \mathrm{~g}$ (Pharmamedia, Hartge ingredients, Humburg, adjusted at $\mathrm{pH} 7.5$ ). The cultures were grown at $28^{\circ} \mathrm{C}$ for 72 hours under constant shaking $(120 \mathrm{rpm})$ using a rotatory shaker. The flasks containing the culture of Z26 were transferred to inoculate 10L fermentor and the large scale fermentation was performed at an aeration rate of $0.5 \mathrm{vvm}$ and agitation of $1000 \mathrm{rpm}$ for ten days (Boonlarppradab et al., 2011).

About $2 \%$ of a filter aid (Hyphlo Supercel ${ }^{\circledR}$, Johns Mansville) was mixed with the fermentation culture obtained and filtered through a filter press in order to separate the fermentationbrothfrom the mycelium. The culture broth was adjusted to $\mathrm{pH} 5$ (1N HCL) and extracted three time with ethyl acetate. After drying the combined organic phases, using a rotary evaporator, $16.28 \mathrm{~g}$ of crude extract could be obtained.

\section{Fractionation, Purification and Chemical Characterization of Purified Compounds}

The crude extract of the aqueous phase of the Z26 isolate has been the subject of several purification steps. In fact, precise quantities were separated in the first into several fractions by three different chromatographic methods such as, on Sephadex LH 20 column $(90 * 2.5 \mathrm{~cm}$, flow rate: $0.5 \mathrm{ml} / \mathrm{min})(100 \%$ $\mathrm{MeOH}$ ), semi-preparative reverse phase HPLC using C18 column (40g, $50 \mu \mathrm{m}$, flow rate: $20 \mathrm{ml} / \mathrm{min}$, Merck Germany) $(100 \% \mathrm{MeOH})$ and Silica gel column $(40 \mathrm{~g}$, $50 \mu \mathrm{m}$, flow rate: $20 \mathrm{ml} / \mathrm{min}$, Merck Germany) $(100 \%$ $\left.\rightarrow 80 \% \mathrm{CH}_{2} \mathrm{Cl}_{2}-\mathrm{MeOH}\right)$. Then, an analytical HPLC analysis was performed for all fractions and the fractions obtained with the same HPLC spectrum and the same activity were merged. 
The second purification step of the combined fractions was carried out by preparative HPLC using two other columns, namely the PFP column (Luna $5 \mu \mathrm{m}$, $100 \mathrm{~A}, 250 * 10 \mathrm{~mm}$; flow rate: $4.5 \mathrm{ml} / \mathrm{min}$ ) (acetonitril $(\mathrm{A}) / \mathrm{H}_{2} \mathrm{O}(\mathrm{B}): 40 \%(\mathrm{~A}) \rightarrow 100 \%$ (A) during $50 \mathrm{~min}$, Thereafter $100 \%$ (A) from $50,1 \mathrm{~min}$ to $55 \mathrm{~min}$ then $35 \%$ (A) around $60 \mathrm{~min})$ and $\mathrm{C} 18$ column $(5 \mu \mathrm{m}, 250 * 20 \mathrm{~mm}$; flow rate: $4.5 \mathrm{ml} / \mathrm{min}$ ) (acetonitril $(\mathrm{A}) / \mathrm{H}_{2} \mathrm{O}(\mathrm{B}): 41 \%(\mathrm{~A})$ $\rightarrow 100 \%$ (A) during $60 \mathrm{~min}$, Thereafter $100 \%$ (A) from $60,1 \mathrm{~min}$ to $65 \mathrm{~min}$ and $36 \%$ (A) around $70 \mathrm{~min}$ ). Finally, we obtained 8 pure compounds but only two had a nonpolyenic antifungal activity named ZD1 $(6.03 \mathrm{mg})$ and ZD2 ( $2 \mathrm{mg}$ ). The compound structures were fully elucidated by 1D and 2D NMR analyses and the molecular weight was determined using masse spectroscopy (ESI-MS).

\section{Results and Discussion}

\section{Screening for Non-Polyenic Antifungal Activity}

Severalactinomycetes isolates tested in this study appeared to be promising source of antifungal metabolites. Among 480 isolates, more than 28\% produced molecules with antifungal activity against one or more Candida test strains (Fig. 1). The highest percentage of activity was noted for Candida albicans L4 and C. glabrata L7 with a percentage higher than $30 \%$. Around $28 \%$ was recorded for C. krusei L10 and
C. albicans L61; and $23 \%$ for C. parapsilosis L18. So, the latter is the most resistant of the yeasts used (Fig. 1). However, this percentage is similar to those reported previously (between 10 and $34 \%$ ) in studies on the antimicrobial activity of soil and aquatic actinomycetes (Ouhdouch et al., 2001).

The selected actinomycete isolates with antifungal activity were used in a secondary screening step for the detection of potential nonpolyenic metabolites. Four assays, which are most commonly carried out, were used.

The antifungal activity was observed in 60 isolates; 14 of them exhibited activity against both Candida tropicalis R2 and Pythium irregulare. The ability of these isolates to inhibit the growth of some Gram positive bacteria was tested. Using the antibacterial activity against bacteria lacking sterols (target of polyenes) in their cell wall, favors the selection of the non-polyenic substances (Fguira et al., 2002).

According to the data in Table 2 and 3, 6 of these 14 actinomycetes isolates showed high antifungal and antibacterial activity in particular against Gram positive bacteria compared with the Gram negative ones. This different sensitivity could be attributedto morphological and chemical composition differences such as the membrane of Gram positive bacteria having lipopolysaccharides which could make the cell wall impermeable to bioactive substances (Gebreyohannes et al., 2013).

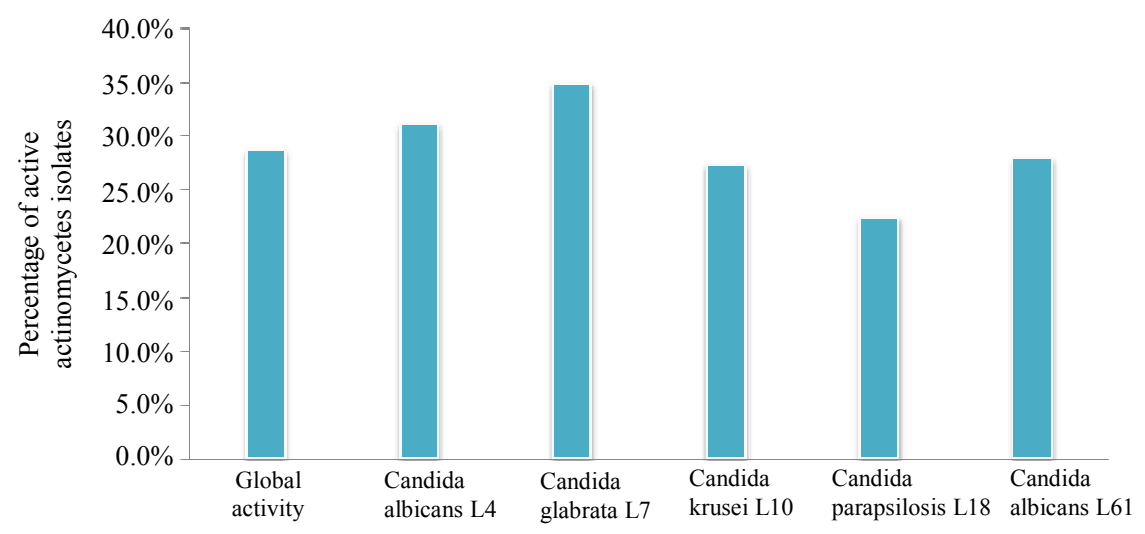

Fig. 1: Percentage of global antifungal activity against yeast test microorganism

Table 2: Antifungal activity of selected actinomycetes isolates against some pathogenic yeast strains*

\begin{tabular}{|c|c|c|c|c|c|}
\hline \multirow[b]{2}{*}{$\begin{array}{l}\text { Reference of } \\
\text { isolates }\end{array}$} & \multicolumn{5}{|c|}{ Antifungal activity (in $\mathrm{mm}$ ) against } \\
\hline & $\begin{array}{l}\text { Candida albicans } \\
\text { L4 }\end{array}$ & $\begin{array}{l}\text { Candida glabrata } \\
\text { L7 }\end{array}$ & $\begin{array}{l}\text { Candida krusei } \\
\text { L10 }\end{array}$ & $\begin{array}{l}\text { Candida parapsilosis } \\
\text { L18 }\end{array}$ & $\begin{array}{l}\text { Candida albicans } \\
\text { L61 }\end{array}$ \\
\hline $\mathrm{Z} 26 * *$ & 17 & 19 & 15 & 15 & 19 \\
\hline B $39 * *$ & 19 & 12 & 14 & 19 & 12 \\
\hline $\mathrm{AS} 25^{* *}$ & 13 & 15 & 14 & 13 & 15 \\
\hline OE $25 / 1 * *$ & 15 & 10 & 16 & 15 & 10 \\
\hline B $53 * *$ & 15 & 14 & 11 & 14 & 13 \\
\hline B $19 * *$ & 14 & 11 & 12 & 11 & 12 \\
\hline
\end{tabular}

*The yeast strains were provided by the Moroccan Co-ordinated Collection of Microorganisms

**Reference number in the collection of actinomycetes of the "Laboratory of biology and Biotechnology of microorganisms, Semlalia Faculty of Sciences Marrakesh, Cadi Ayyad University Morocco" 
Table 3: Results of four step screening method for potential non-polyenic antifungal actinomycete isolates

\begin{tabular}{|c|c|c|c|c|c|c|c|c|c|c|}
\hline \multirow[b]{2}{*}{ Isolates } & \multicolumn{5}{|c|}{ Antibacterial activity } & \multicolumn{2}{|c|}{ Antifungal activity } & \multicolumn{3}{|c|}{ Ergosterol effect $* *$} \\
\hline & S. aureus & M. luteus & B. cereus & P. aeruginosa & E. coli & C. tropicalis $R 2$ & P. irregulare & without & with & spectra \\
\hline Z 26* & + & + & + & & & + & + & 17 & 16 & NP \\
\hline B $39 *$ & + & + & + & & & + & + & 19 & 19 & NP \\
\hline AS $25^{*}$ & + & + & + & & & + & + & 13 & 12 & NP \\
\hline OE $25 / 1^{*}$ & + & + & + & & & + & + & 15 & 13 & NP \\
\hline B $53 *$ & + & + & + & + & & + & + & 15 & 16 & NP \\
\hline B $19^{*}$ & + & + & + & & & + & + & 14 & 8 & NP \\
\hline Amphotericin $\mathrm{B}^{* * *}$ & ND & ND & ND & ND & ND & & & 16 & 10 & $\mathrm{P}$ \\
\hline
\end{tabular}

*Reference number in the collection of actinomycetes of the "Laboratory of biology and Biotechnology of microorganisms, Semlalia Faculty of Sciences Marrakesh, Cadi Ayyad University Morocco

**Inhibition zones in $\mathrm{mm}$ with or without ergosterol at $50 \mathrm{mg} / \mathrm{ml}$ in Sabouraud medium

$* * * 20 \mu \mathrm{g} /$ well or disc

NP: Non Polyenic; P: Polyenic

The plasma membrane of yeast is composed of sterols which are the targets of polyenic antifungal substances; hence, the incorporation of exogenous ergosterol in the culture medium interferes with the activity of the potential polyenic substances produced by the isolates and reduces the inhibition diameters in the second screening assay. For nonpolyenic molecules, the diameter of the inhibition zones remains constant because no interaction occurs (Thakur et al., 2007). All isolates except B19 showed a reduction in the diameters of the inhibition zones (Table 3).

Spectroscopic techniques have been used to distinguish between polenic and non-polyenic compounds (Saadoun et al., 2009). The analysis of the UV spectra of the active extracts showed no polyenic absorption bands (Table 3) with a characteristic series of peaks between 260 and $405 \mathrm{~nm}$ (Boussaber et al., 2014).

On the other hand, B19 isolate showed the first criteria of strain with nonpolyenic antifungal and its extract did not show polyene type UV-visible spectra. However, the size of the inhibition zones was significantly reduced after exogenous ergosterol addition. This couldbe explained by a coproduction of polyene and nonpolyene compounds by the same strain (Lemriss et al., 2003).

After the second screening, the selected actinomycete isolate Z26 showed astrong non-polyenic antifungal activity against all test microorganisms. Thus it was further characterized based on, morphological, physiological appearance and molecular characterization.

\section{Taxonomy of the Selected Isolate Z26}

The isolate Z26 showed abundant mycelia and good growth on all media used after 2 weeks at $30^{\circ} \mathrm{C}$, except in ISP 1, in which slow growth was observed (Table 4). The aerial mycelium was yellowish white on ISP 1 and grayish white on ISP 2, ISP 3, ISP 4 and Bennett. The substrate mycelium was yellowish white on ISP1, ISP3 and Bennett, but light green on ISP2 and ISP4. Diffusible and melanoid pigments were produced only on ISP 1 and ISP 6 respectively.

The physiological properties of the isolate Z26 are shown in Table 5. Its optimal growth was observed at $28-30^{\circ} \mathrm{C}$ and between $\mathrm{pH} 6$ and 7. It was able to grow from $1.5 \%$ of $\mathrm{NaCl}$ but not higher than $7 \%$. It was able to hydrolyze D-Arabinose, Glucose, L-Rhamnose, Mannitol and L-Proline, but not Fructose and L-Asparagine.

Based on the molecular identification of 16S RNA sequence, the morphological and the chemical characteristics, the isolate Z26 belonged to the genus Streptomyces. Its position at the 16S rDNA Streptomyces tree is shown in Fig. 2. The identification level was $99.43 \%$ with Streptomyces phytohabitans, but strains showing a 16S RNA sequence identity of $100 \%$ do not automatically belong to the same species (Whitman et al., 2012).

However, our isolatecould be distinguished from Streptomyces phytohabitans by some phenotypic properties, for example, Streptomyces phytohabitans produces a pink diffusible pigment but our strain produces a light green one. There are additional differences in several morphological properties, including color of substrate and aerial mycelia (Guang-Kai et al., 2012).

\section{Structural Elucidation of the Two Molecules ZDI and ZD2}

Compound ZD1 was purified as a white amorphous powder with a molecular formula $\mathrm{C}_{62} \mathrm{H}_{100} \mathrm{O}_{24}$ determined on the basis of the results of HRMS data analysis $(\mathrm{m} / \mathrm{z}$ $1251.6504 \quad[\mathrm{M}+\mathrm{Na}]^{+}$, calculated for $\mathrm{C}_{62} \mathrm{H}_{100} \mathrm{O}_{24} \mathrm{Na}$ : $1251.6497 \mathrm{~g} / \mathrm{mol}$ ). It is easily soluble in $\mathrm{MeOH}$ and it has $10.594 \mathrm{~min}$ as retention time and maxima in the UV spectrum at 222, 260, $295 \mathrm{~nm}$ (Fig. 3 and 4). 
Table 4: Differential phenotypic characteristics of Streptomycessp. Z26 on different ISP media after 2 weeks of incubation at $30^{\circ} \mathrm{C}$

\begin{tabular}{llll}
\hline Medium & Growth * & Aerialmycelium & Subsrtatemycelium \\
\hline Tryptone-yeast extract agar (ISP1) & + & Yellowish white & Yellowish white \\
Yeast extract-malt extract agar(ISP2) & +++ & Grayish white & Light green \\
Oatmeal agar(ISP3) & +++ & Grayish white & Yellowish white \\
Inorganic salt-starch agar(ISP4) & +++ & Grayish white & Light green \\
Bennett agar & +++ & Grayish white & Yellowish white \\
\hline
\end{tabular}

*: +++ Abundant, ++ moderate and + less

Table 5: Physiological properties of Streptomyces $s p$. Z26 and S. phytohabitansusing different criteria

\begin{tabular}{|c|c|c|}
\hline Characteristics & Streptomyces sp. Z26 & S.phytohabitans \\
\hline Growthat $25-37^{\circ} \mathrm{C}$ & + & ++ \\
\hline Growthat $\mathrm{pH} 9.0$ & - & - \\
\hline $\begin{array}{l}\mathrm{NaCl} \text { tolerance } 1.5-7 \% \text { (optimal) } \\
\text { utilisation of: }\end{array}$ & + & + \\
\hline D - Arabinose & + & + \\
\hline Glucose & + & + \\
\hline L-Rhamnose & + & + \\
\hline Mannitol & + & + \\
\hline Fructose & - & - \\
\hline L-Asparagine & - & - \\
\hline L-Proline & + & ND \\
\hline
\end{tabular}

Tests: + positive, - negative.

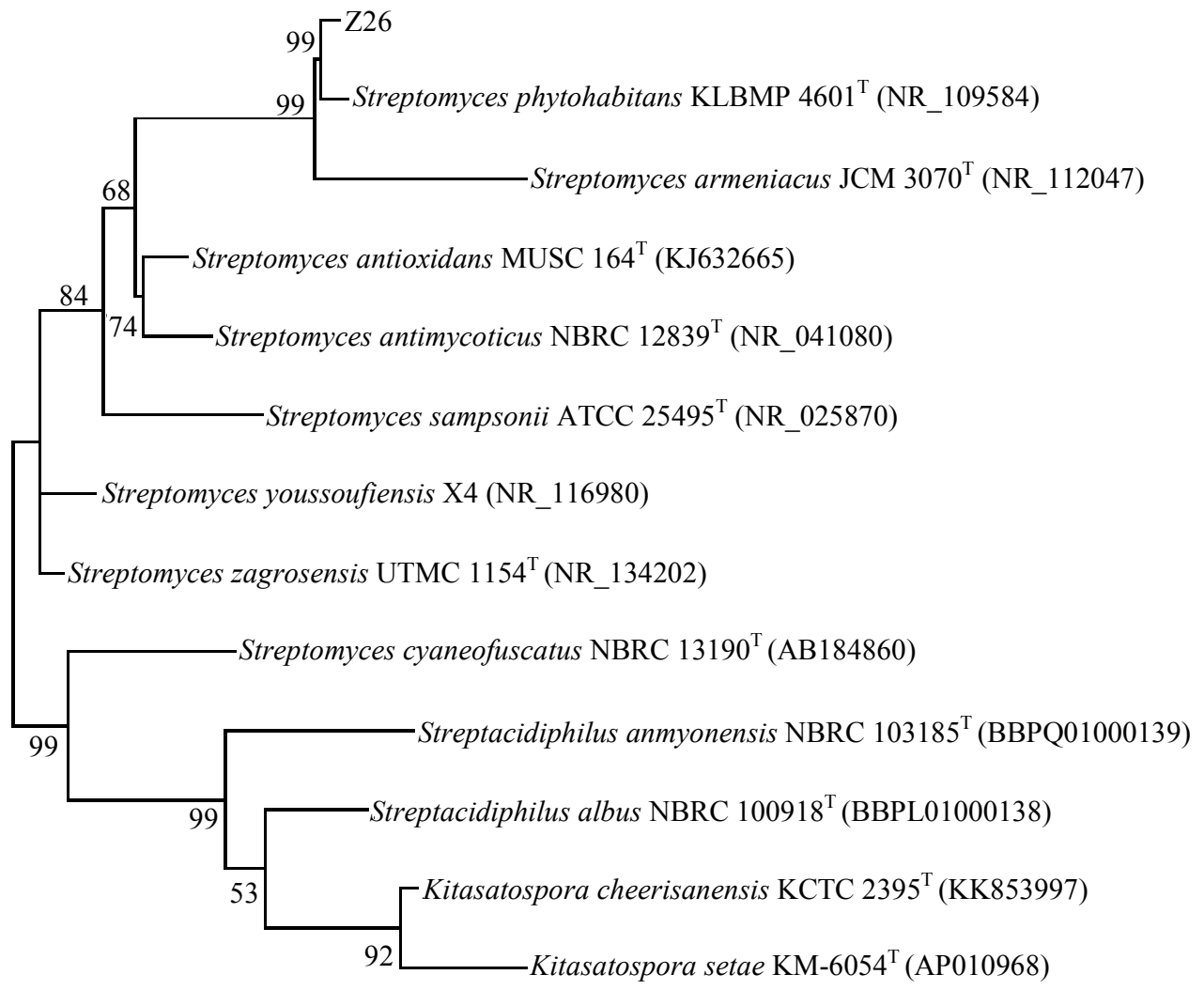

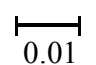

Fig. 2: Phylogenic tree based on 16S rRNA gene sequence showing the relations between strain Z26 and type species of the genus Streptomyces. The numbers at the nodes indicate the levels of bootstrap support based on neighbor-joining analyses of 1000 resampled data sets (only values $>50 \%$ are shown). Bar, 0.01 substitution per nucleotide position 


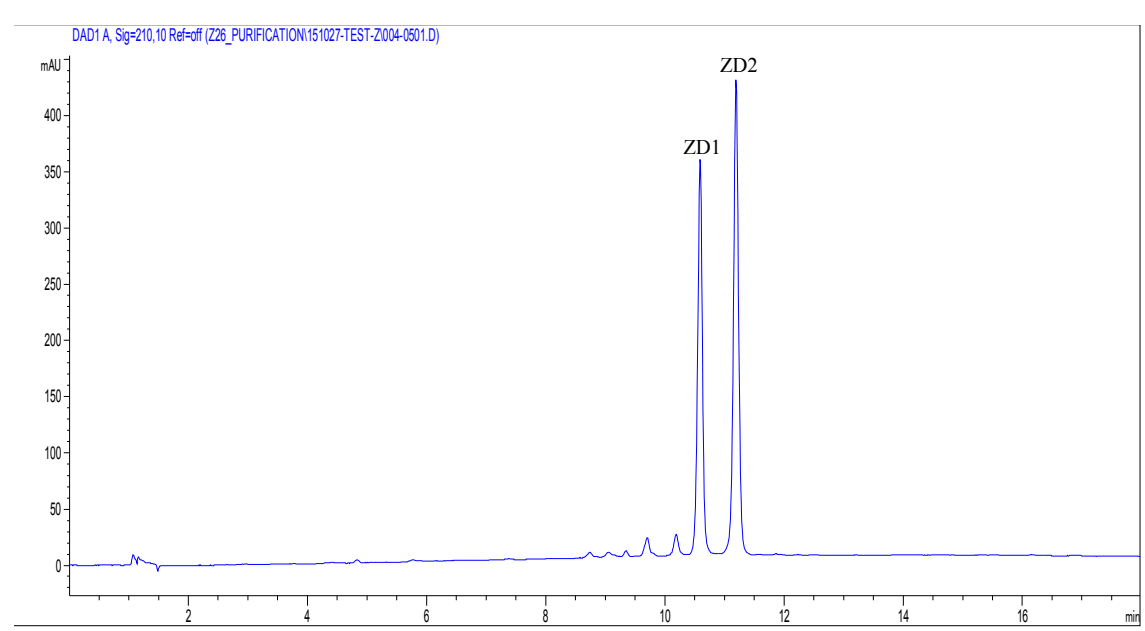

Fig. 3: Analytical HPLC Spectrum of the two derivatives of Novonestmycin A (ZD1) and Novonestmycin B (ZD2) monitored at $210 \mathrm{~nm}$

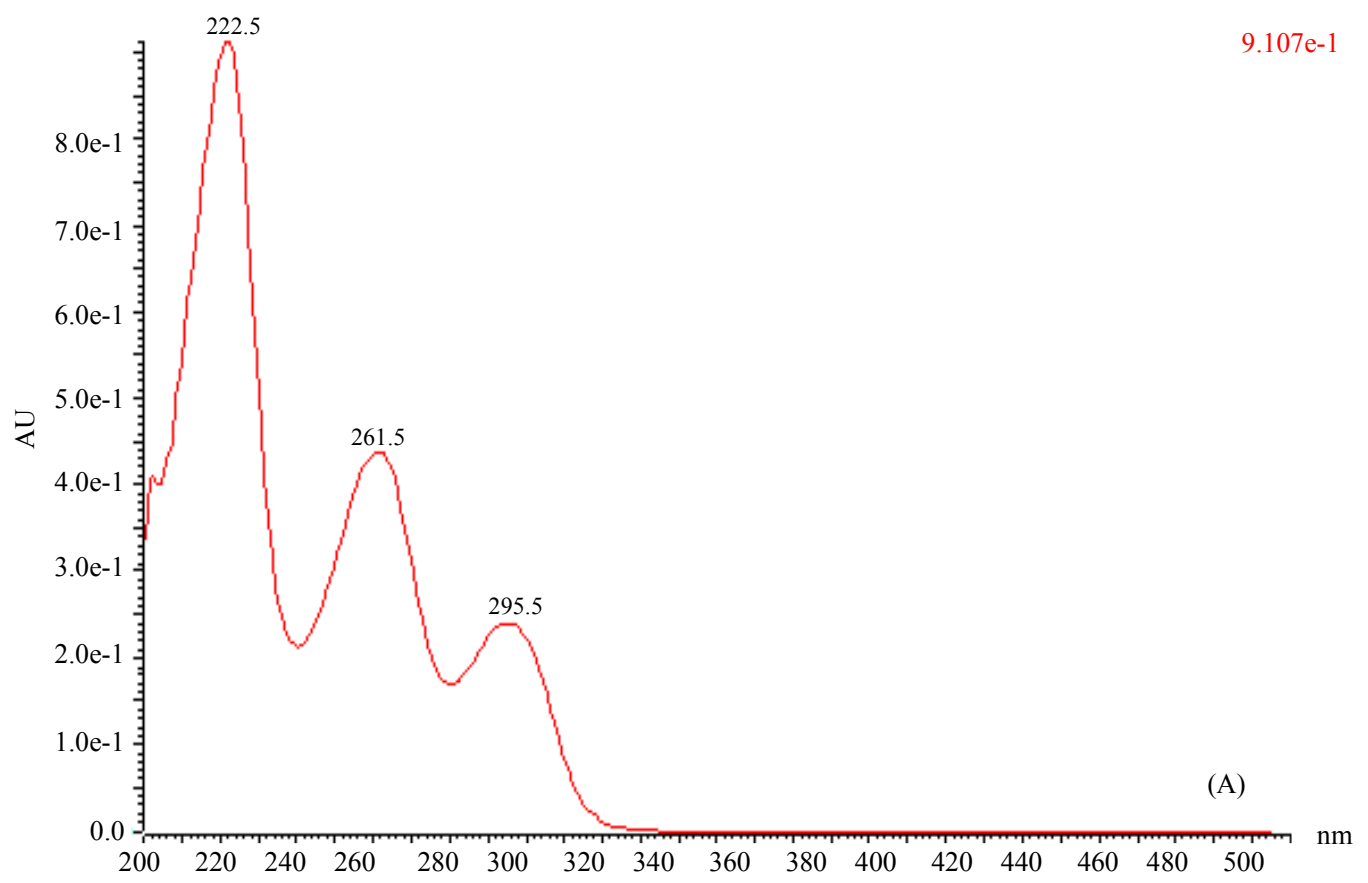

Fig. 4: UV-visible spectrum of NovonestmycinA (ZD1)

The ${ }^{13} \mathrm{C}$ NMR data shows the presence of height quaternary carbons (including a hemiacetal carbon around $\delta_{\mathrm{c}} 99.9$ and four carbonyl carbons at $\delta_{\mathrm{c}} 208.5, \delta_{\mathrm{c}} 173.9, \delta_{\mathrm{c}}$ 168.9 and $\delta_{\mathrm{c}} 167.8$ ), eight aromatic carbons, seven aliphatic methines, eighteen oxygenated methines with an anomeric carbon at $\delta_{\mathrm{c}} 98.5$, twelve methylenes and eleven methyl carbons with methoxycarbon at $\delta_{\mathrm{c}} 61.4$ (Fig. 6).

The ${ }^{1} \mathrm{H}$ NMR spectrum shows three aromatic protons at $\delta_{\mathrm{H}} 6.82\left(1 \mathrm{H}, \mathrm{d}, \mathrm{J}=9.0 \mathrm{~Hz}, \mathrm{H}-6{ }^{\prime \prime}\right), \delta_{\mathrm{H}} 7.46(1 \mathrm{H}, \mathrm{d}, \mathrm{J}=$ $2.0 \mathrm{~Hz}, \mathrm{H}-3$ "') and $7.46(1 \mathrm{H}, \mathrm{dd}, \mathrm{J}=9.0,2.0 \mathrm{~Hz}, \mathrm{H}-7$ ' '), This implies that the structure of ZD1 contains a 1,3,4tri-substituted benzene. The COSY ${ }^{1} \mathrm{H}-{ }^{1} \mathrm{H}$ spectrum presents a series of correlations of three partial structural units called: H-16 to H-39, H-16 to H-39 and H-1' to H-6'.
Similarly, compound ZD2 was purified as a white amorphous powder with the formula $\mathrm{C}_{68} \mathrm{H}_{110} \mathrm{O}_{26}$ and molecular weight $\mathrm{m} / z 1365.7174[\mathrm{M}+\mathrm{Na}]^{+}$(calculated for $\mathrm{C}_{68} \mathrm{H}_{110} \mathrm{O}_{26} \mathrm{Na}: 1365.7178 \mathrm{~g} / \mathrm{mol}$ ). It is also soluble in Methanol; his retention time is $11.200 \mathrm{~min}$ and 222, 260, 290 as picks on the UV spectrum (Fig. 3 and 5).

Comparing the NMR ${ }^{13} \mathrm{C}$ spectrum of ZD1 and ZD2, The evident differences were the addition of six carbons including one methyl carbon, one anomeric carbon, two methylenes carbons and two oxygenated carbon methines (Fig. 6). The $\mathrm{COSY}{ }^{1} \mathrm{H}-{ }^{1} \mathrm{H}$ spectrum indicates the existence of a correlation between H-1", and C-5" " which reveals the presence of one fragment of 2,3,6-trideoxyhexose which was linked to C-4" by a correlation between $\mathrm{H}-1$ "' to C-4"'. 


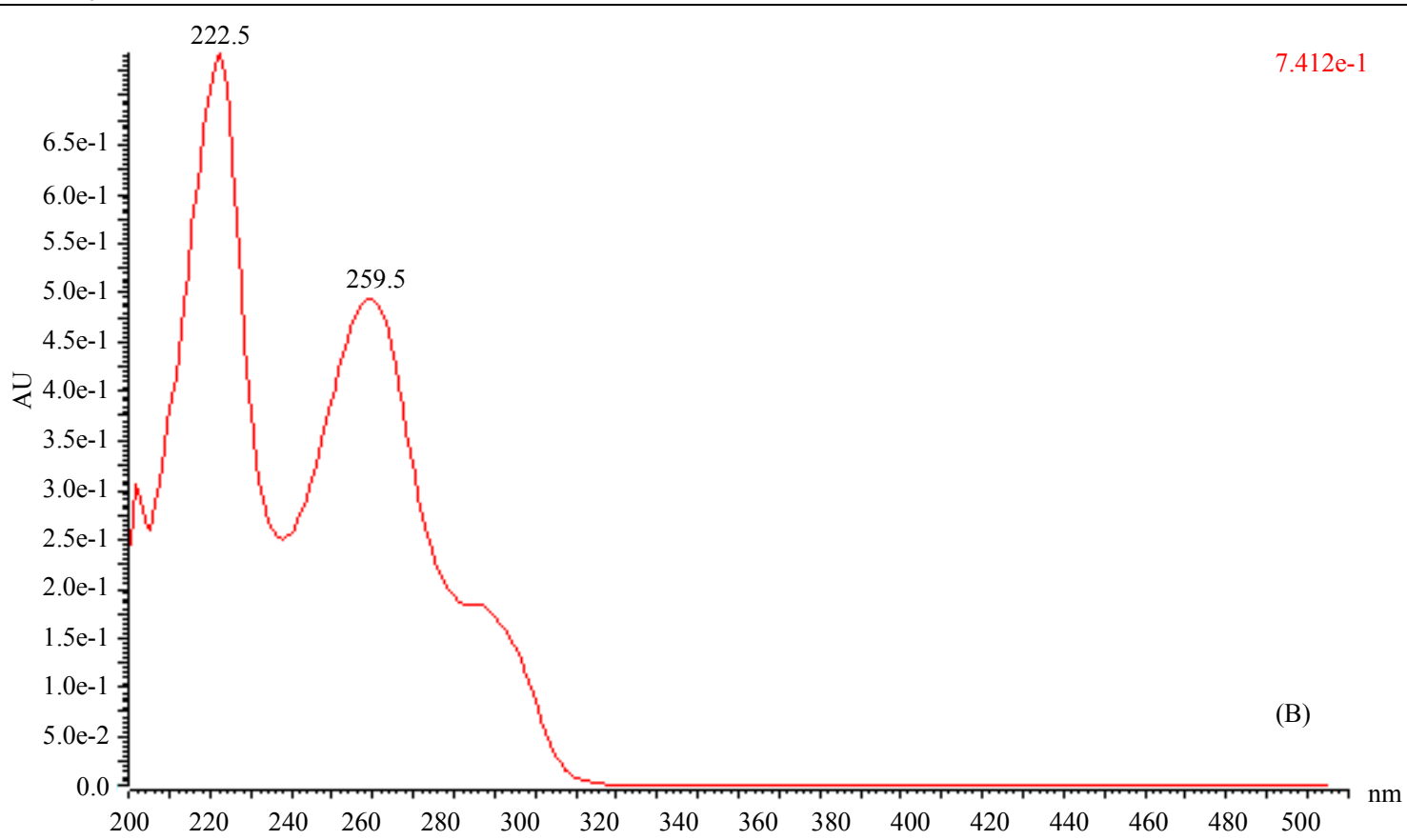

Fig. 5: UV-visible spectrum of Novonestmycin B (ZD2)

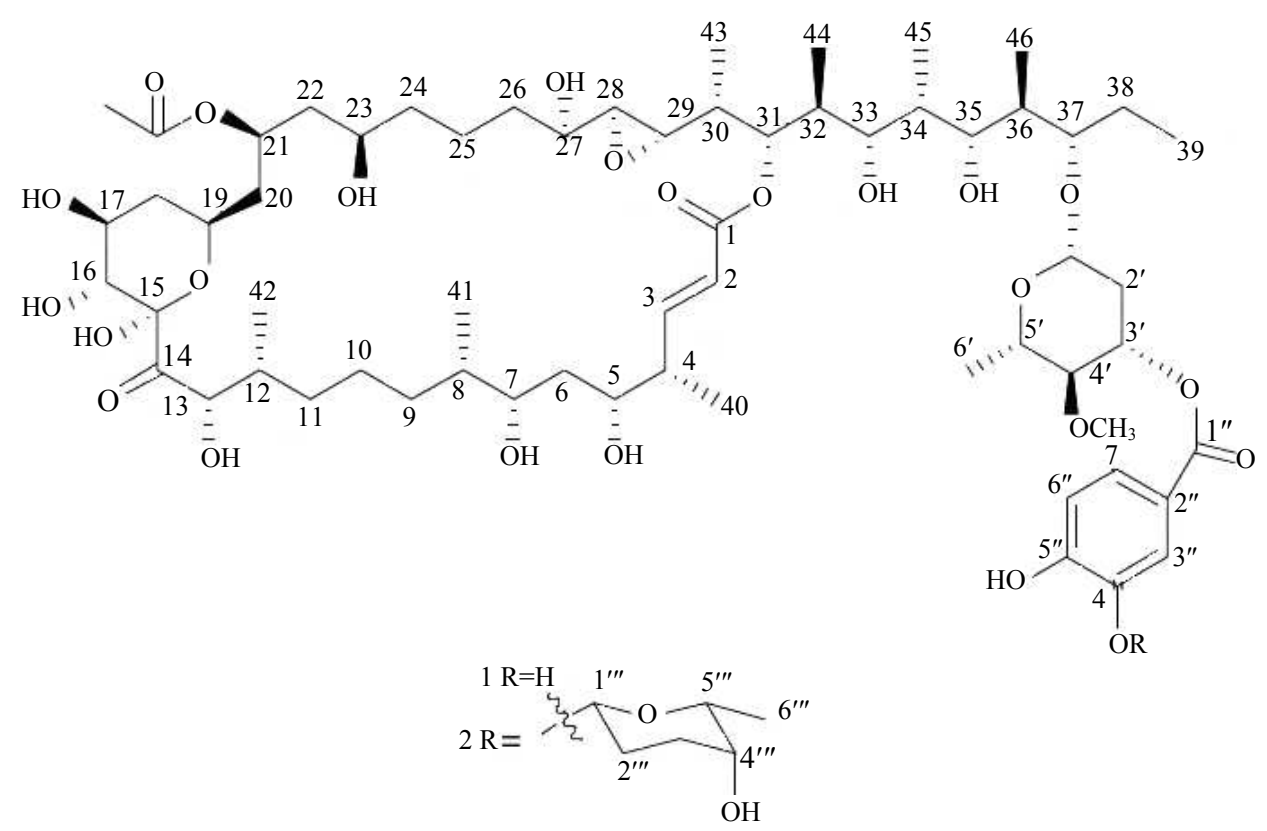

Fig. 6: Chemical structures of the NovonestmycinA (ZD1) and Novonestmycin B (ZD2)

The two compounds ZD1 and ZD2 were newly discovered and whose names are Novonestmycins A and B respectively (Wan et al., 2015). Novonestomycins A and B have a closer structure related to the structure of Notoneesomycin A, the 32-member macrolide antibiotics produced by Notonesogenes 647-AV1 (Sasaki et al., 1986). Novonestomycin B (ZD2) and Notonésomycin A have the same skeleton and the difference between these two compounds is the substitution in the macrolide and the benzene nucleus.
Moreover, the structure of Novonestmycin A (ZD1) was similar to that of Notonesomycin A3, which was elucidated on the basis of HMBC data analysis by revealing the connectivities of the structural units: HMBC correlations from $\mathrm{H}-13$ to $\mathrm{C}-14$ and $\mathrm{H}-16$ to $\mathrm{C}$ 14 which indicates that the ketone group was located at position C-14 (Kihara et al., 1995).

Novonestomycins A and B have a strong antifungal activity against some fungi strains which is similar to that of a structurally related compound named 
liposidolide A, the 36-member macrolide antibiotics produced by Streptomyces sp. RS-28 but Notonomycin A has only a moderate activity (Kihara et al., 1995).

Brasinolide A, another compound with a similar structure, showed only a moderate antifungal activity against Aspergillus niger (Tanaka et al., 1997). These results suggest that 14-ketone groups may be important for the antifungal activity.

\section{Conclusion}

The findings confirm that the Moroccan ecosystems (little or not exploitable) are very rich in microorganisms that are able to produce bioactive molecules which might play a role in future therapeutics. This encourages us to better exploit them in order to discover other new substances.

\section{Acknowledgements}

The principal author is grateful to all those who have participated in this work and it are supported by the German Academic Exchange Service, DAAD Research grants $2015 \mathrm{~N}^{\circ} 57130097$.

\section{Author's Contributions}

All authors equally contributed in this work.

\section{Conflict of Interest Statement}

The authors have declared no conflict of interest.

\section{References}

Atta, H.M., 2010. Production, purification, physicochemical characteristics and biological activities of antifungal antibiotic produced by Streptomyces antibioticus, AZ-Z710. Am. J. Sci. Res., 5: 39-49.

Ayari, A., H. Morakchi and K.G. Djamila, 2012. Identification and antifungal activity of Streptomyces sp. S72 isolated from Lake Oubeira sediments in North- East of Algeria. Afr. J. Biotechnol., 11: 305-311. DOI: $10.5897 / A J B 10.2345$

Barakate, M., Y. Ouhdouch, K. Oufdou and C. Beaulieu, 2002. Characterization of rhizospheric soil streptomycetes from Moroccan habitats and their antimicrobial activities. World J. Microbiol. Biotechnol., 18: 49-54. DOI: 10.1023/A:1013966407890

Behie, S.W., B. Bonet, V.M. Zacharia, D.J. McClung and M.F. Traxler, 2016. Molecules to ecosystems: Actinomycete natural products in situ. Front. Microbiol., 7: 1-11.

DOI: $10.3389 /$ fmicb.2016.02149
Fguira, F.L.B., S. Bejar and L. Mellouli, 2002. Isolation and screening of Streptomyces from soil of Tunisian oases ecosystem for nonpolyenic antifungal metabolites. Afr. J. Biotechnol., 11: 7512-7519. DOI: $10.5897 / A J B 11.2180$

Benouagueni, S. and D.G. Kirane, 2016. Molecular identification and characterization of active actinomycete strain isolated from El Mellah Lake of El Kala. J. Chem. Pharm. Res., 8: 579-584.

Whitman, W.B., M. Goodfellow, P. Kämpfer, H.J. Busse and M.E. Trujillo et al., 2012. Bergey's Manual of Systematic Bacteriology. 2nd Edn., Springer Science \& Business Media, ISBN-10: 0387682333, pp: 2083.

Boonlarppradab, C., C. Suriyachadkun, S. Suphothina, P. Tobwor, 2011. Bireticulol, a bioactive isocoumarin dimer from Streptomyces sp. BCC24731. J. Antibiot. (Tokyo), 64: 267-270. DOI: 10.1038/ja.2010.171

Boussaber, E.A., S. Brahim, S. El Idrissi, I.M. Kadmiri and L. Hilali et al., 2014. Extraction and preliminary characterization of bioactive molecules produced by a new Streptomyces strain. J. Environ. Treat. Tech., 2: $50-55$.

Diekema, D.J. and M.A. Pfaller, 2004. Nosocomial Candidemia: An Ounce of Prevention Is Better Than a Pound of Cure. Infect. Control Hospital Epidemiol., 25: 624-626.

DOI: $10.1086 / 502451$

Dutta, V., W.V. Lyngdoh, I. Bora, B. Choudhury and A.B. Khyriem et al., 2015. Characterization of Candida species from Intensive Care Unit Isolates in a Tertiary Care Centre in North-East India: A retrospective study. Int. J. Med. Public Health, 5: 312-316. DOI: 10.4103/2230-8598.165961

Gebreyohannes, G., F. Moges, S. Sahile and N. Raja, 2013. Isolation and characterization of potential antibiotic producing actinomycetes from water and sediments of Lake Tana, Ethiopia. Asian Pacific J. Trop. Biomed., 3: 426-435. DOI: 10.1016/S2221-1691(13)60092-1

Guang-Kai, B., S. Qin, B. Yuan, Y.J. Zhang and K. Xing et al., 2012. Streptomyces phytohabitans sp. nov., a novel endophytic actinomycete isolated from medicinal plant Curcuma phaeocaulis. Antonie Van Leeuwenhoek, 102: 289-296. DOI: $10.1007 / \mathrm{s} 10482-012-9737-8$

Hashimoto, Y., 2007. Development of novel expression systems for actinomycetes. Actinomycetologica, 21: 70-75. DOI: $10.3209 /$ saj.SAJ210204

Ismet, A., N.A. Bukhari, K. Perveen and M.A. Bakir, 2012. Antifungal activity of some actinomycetes isolated from Riyadh soil, Saudi Arabia: An evaluation for their ability to control Alternaria caused tomato blight in green house pot trial. African J. Agric. Res., 7: 2042-2050. DOI: $10.5897 / A J A R 12.398$ 
Kathiravan, P., R. Sabarinathan, R. Subbaiya and M.M. Selvam, 2016. Investigation on sugar cane field actinomycetes of Erode district. Res. J. Pharm. Biol. Chem. Sci., 7: 1144-1154.

Kihara, T., H. Koshino, Y.C. Shin, I. Yamaguchi and K. Isono, 1995. Liposidolide A, a new antifungal macrolide antibiotic. J. Antibiot. (Tokyo), 48: 1385-1387. DOI: 10.7164/antibiotics.48.1385

Kumar, V., A. Bharti, O. Gusain and G.S. Bisht, 2010. An improved method for isolation of genomic dna from filamentous actinomycetes. J. Eng. Technol. Manage., 2, 10-13.

Laniado-Laborín, R. and M.N. Cabrales-Vargas, 2009. Amphotericin B: Side effects and toxicity. Rev. Iberoamericana Micol., 26: 223-227. DOI: 10.1016/j.riam.2009.06.003

Lee, J.Y. and B.K. Hwang, 2002. Diversity of antifungal actinomycetes in various vegetative soils of Korea. Can. J. Microbiol., 48: 407-417.

Lemriss, S., F. Laurent, A. Couble, E. Casoli and J.M. Lancelin et al., 2003. Screening of nonpolyenic antifungal metabolites produced by clinical isolates of actinomycetes. Canadian J. Microbiol., 49: 669-674. DOI: $10.1139 /$ w03-088

Manivasagan, P., J. Venkatesan, K. and S.K. Kim, 2013. Marine actinobacterial metabolites: Current status and future perspectives. Microbiol. Res., 168: 311-332. DOI: 10.1016/j.micres.2013.02.002

Manivasagan, P., J. Venkatesan, K. Sivakumar and S.K. Kim, 2014. Pharmaceutically active secondary metabolites of marine actinobacteria. Microbiol. Res., 169: 262-278.

DOI: 10.1016/j.micres.2013.07.014

McNeil, M.M., S.L. Nash, R.A. Hajjeh, M.A. Phelan and L.A. Conn et al., 2001. Trends in mortality due to invasive mycotic diseases in the United States, 1980-1997. Clin. Infect. Dis., 33: 641-647. DOI: $10.1086 / 322606$

Ouhdouch, Y., M. Barakate and C. Finance, 2001. Actinomycetes of Moroccan habitats: Isolation and screening for antifungal activities. Eur. J. Soil Biol., 37: 69-74. DOI: 10.1016/S1164-5563(01)01069-X
Procópio, R.E., I.R. da Silva, M.K. Martins, J.L. de Azevedo and J.M. de Araújo, 2012. Antibiotics produced by Streptomyces. Brazilian J. Infect. Dis., 16: 466-471. DOI: 10.1016/j.bjid.2012.08.014

Saadoun, I., F. Al-Momani, Q. Ababneh and S. Bonjar, 2009. Comparative UV-spectra of fermented cultural extract of antifungal-active Streptomyces isolates recovered from different ecological habitats. Curr. Trends Biotechnol. Pharm., 3: 155-161.

Sasaki, T., K. Furihata, A. Shimazu, H. Seto and M. Iwata et al., 1986. A novel macrolide antibiotic, notonesomycin A. J. Antibiot. (Tokyo), 39: 502-509.

Suardana, I.W., 2014. Analysis of nucleotide sequences of the 16S rRNA gene of novel Escherichia coli strains isolated from feces of human and Bali cattle. J. Nucleic Acids, 2014: 1-7. DOI: $10.1155 / 2014 / 475754$

Tanaka, Y., H. Komaki, K. Yazawa, Y. Mikami and A. Nemoto et al., 1997. Brasilinolide A, a new macrolide antibiotic produced by Nocardia brasiliensis: Producing strain, isolation and biological activity. J. Antibiot. (Tokyo), 50: 1036-1041. DOI: 10.7164 antibiotics.50.1036

Thakur, D., A. Yadav, B.K. Gogoi and T.C. Bora, 2007. Isolation and screening of Streptomyces in soil of protected forest areas from the states of Assam and Tripura, India, for antimicribial metabolites. J. Mycol. Med., 17: 242-249.

DOI: 10.1016/j.mycmed.2007.08.001

Vandeputte, P., S. Ferrari and A.T. Coste, 2012. Antifungal resistance and new strategies to control fungal infections. Int. J. Microbiol., 2012: 1-27. DOI: $10.1155 / 2012 / 713687$

Wadetwar, R.N., J.L. Chaturvedi, E. Zone and H. Road, 2013. Isolation and characterisation of bioactive actinomycetes from soil in and around Nagpur. iIternational J. Pharm. Sci. Res., 4: 1428-1433.

Wan, Z., W. Fang, L. Shi, K. Wang and Y. Zhang et al., 2015. Novonestmycins A and B, two new 32membered bioactive macrolides from Streptomyces phytohabitans HBERC-20821. J. Antibiot. (Tokyo), 68: 185-190. DOI: 10.1038/ja.2014.123 